\title{
Ley de armas \\ Privatización y comercialización de la seguridad ciudadana
}

\author{
Henry Campos ${ }^{1}$ \\ José María Tojeira SJ. ${ }^{2}$
}

Resumen

Según el estudio Activa-IUDOP, en el gran San Salvador se producen alrededor de 1400 muertes violentas al año, de las cuales el 49.7 por ciento son causadas por armas de fuego. Dentro de este contexto surge la nueva ley de armas que, desde su nacimiento, ha necesitado de reformas. En este artículo, los autores hacen algunas observaciones respecto a esta ley y las agrupan en tres niveles: el jurídico, el de política criminal y el que denominan educativo simbólico. El aporte de la nueva ley al necesario combate de la violencia imperante puede desde ahora calificarse como mínimo, cuando no nulo.

\section{Introducción}

La nueva ley de armas ("Ley de control de armas de fuego, municiones, explosivos y artículos similares") se aprueba en El Salvador en tiempos de violencia. Según el estudio Activa-IUDOP, en el gran San Salvador se producen en tomo a las 1400 muertes violentas al año (1 460 en 1995 y 1335 en 1996). De ellas, el 49.7 por ciento son causadas por armas de fuego. La alta incidencia de las armas de fuego en la morbilidad y mortalidad provoca que se alcancen tasas de 128 homicidios por cada 100000 habitantes y altos gastos en el presupuesto nacional de salud. En el marco de la salud pública, el colegio Médico de El Salvador señala que la cuarta causa de morbilidad e ingreso en los hospitales son las "lesiones y traumas causados por la violencia", muchas de ellas debidas a armas de fuego.

1. Catedrático del Departamento de Ciencias Jurídicas de la Universidad Centroamericana "José Simeón Cañas".

2. Rector de la Universidad Centroamericana "José Simeón Cañas". 
Esta elevada situación de violencia ha venido generando, a lo largo de los últimos años, un importante debate ciudadano. La primera reacción ante el fenómeno de la violencia fue claramente vindicativa: reprimir la violencia con más violencia. En un primer momento poniendo en la pena de muerte una especie de esperanza irreflexiva. En un segundo momento insistiendo en la necesidad de endurecer las leyes. $Y$ en un tercer momento, en el que estamos, oscilando entre el endurecimiento de las leyes y la elaboración de una política criminal unida al fortalecimiento de la policía.

En este contexto, y ausente todavía la elaboración de una política criminal, aparece esta ley de armas. Sin más contexto que el de la violencia cotidiana y los intereses económicos y de seguridad de un reducido grupo de ciudadanos, esta ley ha nacido necesitando reformas desde su nacimiento. Incluso algunas de sus pocas novedades deben ser reformadas, como la extensión al ciudadano común del uso y tenencia de armas largas, hasta hace poco limitada a la Fuerza Armada y fuerzas de seguridad. He aquí las observaciones que agrupamos en tres niveles: el jurídico, el de política criminal y el que llamamos educativo simbólico, que está en realidad en el trasfondo de toda ley.

\section{Consideraciones jurídicas}

Lo primero que destaca en la elaboración de esta ley es el bajo nivel técnico-jurídico del legislador. Aunque evidentemente los diputados no están obligados a conocer sobre derecho, deberían contar con asesorías más eficientes y con un cuerpo técnico que facilitara la coherencia y sincronía de la legislación con los cuerpos y doctrina jurídica existente. La tendencia a poner en la sección jurídica de la Asamblea a personas más connotadas por su fidelidad partidaria que por sus conocimientos jurídico-profesionales incide en la enmarañada situación de nuestras leyes. La exposición de las siguientes observaciones jurídicas no sólo constituye motivo de reforma y mejoramiento de la ley, sino que es simultáneamente un llamado al mejoramiento técnico de la elaboración del cuerpo legal que realiza la Asamblea.

(a) $\mathrm{La}$ constante referencia a intervenciones de la Fuerza Armada en los controles y supervisión en la presente ley, derivan del artículo 217 de la Constitución que establece:

La fabricación, importación, exportación, tenencia y portación de armas, municiones, ex- plosivos y artículos similares, sólo podrán efectuarse con la autorización y bajo la supervisión directa del Órgano Ejecutivo, en el Ramo de Defensa. Una ley especial regulará esta materia.

Las constituciones anteriores más cercanas sólo otorgaban facultades a la Fuerza Armada para el control de importación y fabricación de armas de guerra, dejando de lado la comercialización, tenencia y portación, que podía definirse conforme a la ley. Para el caso, la Constitución de 1950 expresaba en el artículo 117 que "La importación y fabricación de armas y elementos de guerra sólo podrán efectuarse con licencia y bajo la fiscalización del Poder Ejecutivo". Igual redacción mantuvo la Constitución de 1962. El peso mayor de la Fuerza Armada contradice la actual y justa tendencia a separar funciones de ejército y seguridad pública. El hecho de que en constituciones anteriores se mantuvieran con mayor claridad separadas las funciones debe hacemos reflexionar sobre la necesidad de reformas constitucionales sobre este punto.

(b) El artículo 16 de la presente ley establece que las personas que se dediquen al comercio deben carecer de antecedentes policíacos. También el art. 23 de la misma ley expresa como requisito para obtener licencias de uso, reparación de armas de fuego o recarga de munición, carecer de antecedentes policiales. Sin embargo, no hay autorización para llevar registros criminales para estos efectos, sino exclusivamente para la elaboración de una estadística criminológica nacional, tal como define las Funciones de Policía el art. 23 de la Ley Orgánica de la Policía Nacional Civil, en su numeral 17: "Acopiar y ordenar datos para la elaboración de una estadística criminológica nacional".

Por lo tanto, es necesario que se autorice a la Policía Nacional Civil una ley a llevar registros policiales para los efectos indicados en la presente normativa.

(c) Hay una constante referencia a los reglamentos para regular incluso lo relativo a derechos subjetivos, cuando la jurisprudencia se pronuncia por exigir la existencia de una ley para limitar derechos. La reserva de ley es uno de los principios más violados por nuestros legisladores. Por ejemplo, el art. 18 de la ley plantea que las personas autorizadas para comercializar armas de fuego que no lleven un inventario especial, serán objeto de la aplicación de las sanciones establecidas en el Re- 
glamento. Asimismo el artículo 62 prohibe la portación de armas de fuego en determinados lugares y amenaza con sanciones contenidas en esta ley y su reglamento. De manera general, el artículo 67 remite al reglamento en lo que respecta a las sanciones.

Otro caso semejante es el del art. 21 que establece que el reglamento de esta ley determinará los límites de las cantidades de armas y municiones que serán compradas y la forma en que el vendedor llevará control para ello. E igualmente en los artículos 23 y 25 se expresa que las licencias y matrículas serán renovadas salvo por inhabilitaciones dispuestas en la presente ley y su reglamento.

El artículo 30 determina que los requisitos y procedimientos para la inutilización permanente de armas serán establecidos en el reglamento respectivo. El art. 31 de la misma ley dispone que para obtener autorización para fabricar armas y otros deberán cumplirse los requisitos de la ley y los establecidos en el reglamento.

Según el artículo 34, para la exportación e importación de armas de fuego el interesado deberá obtener el permiso especial correspondiente de acuerdo con la ley y el reglamento.

El art. 35 establece que las armas que no sean de fuego serán reguladas por el reglamento de esta ley. Y también se remite al reglamento el artículo 39 que determina que los requisitos de seguridad que deben cumplir los depósitos y transporte de armas se establecerán en aquél.

Además de los mencionados, los artículos 41, 45,54 y 56 son prueba de que nuestros legisladores acuden indebidamente al uso de reglamentos.

Finalmente, el artículo 74 remite al reglamento especial lo relativo a la importación, comercio y fabricación de productos químicos utilizables para la elaboración de explosivos y pólvora para fuegos pirotécnicos, y que será regulada por el Ministerio de la Defensa.

En la práctica, con tanto traslado de facultades a los reglamentos, se repite en nuestro país el vicio de traspasar la función de legislar al Órgano Ejecutivo, quien sólo debería tener potestad reglamentaria y no legislativa.

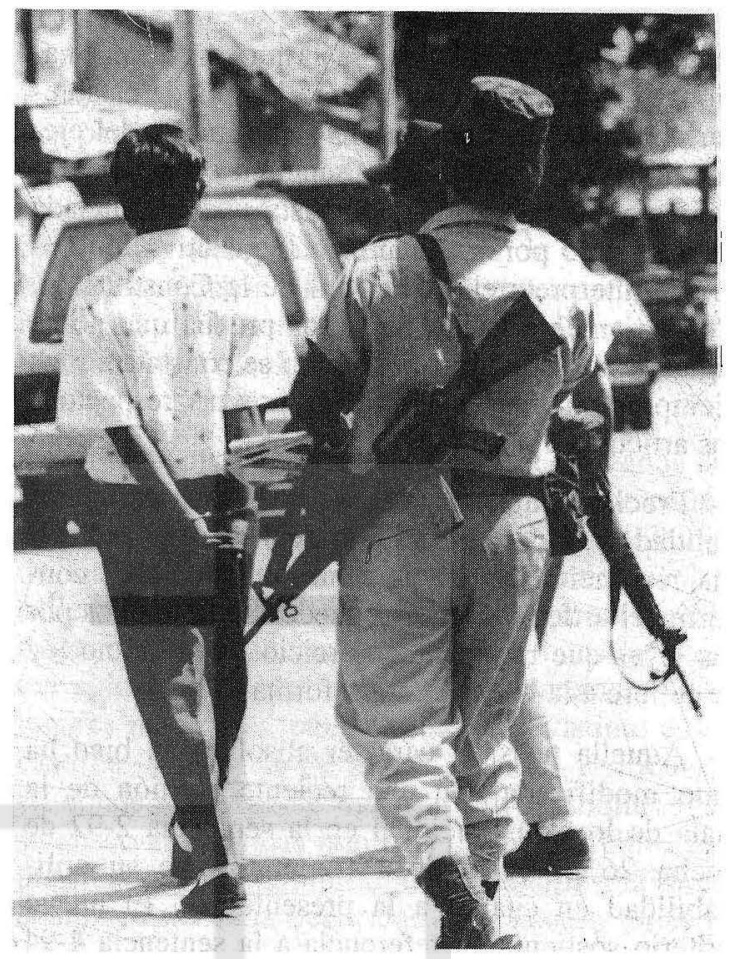

En efecto, en El Salvador hay, fundamentalmente, tres clases de reglamentos:

(a) Autónomos, que son la expresión de facultades de autorregulación. Tal es el caso del Reglamento del Órgano Ejecutivo y el Reglamento de la Asamblea Legislativa. Dichos reglamentos establecen nomas de aplicación interna, es decir, para los funcionarios y empleados correspondientes.

(b) De urgencia y necesidad, dictados para suspender y restablecer las garantías constitucionales, si la Asamblea no está reunida. (Art. 167, No. 6 de la Constitución.)

(c) De aplicación, emitidos para facilitar la aplicación de las leyes y que corresponden a las facultades del Presidente de la República. (Art. 168, No. 14 de la Constitución.)

Ninguno de estos reglamentos puede limitar derechos de los particulares. Y en ese sentido es grave que se establezcan sanciones administrativas en los reglamentos, pues aplicando los principios que informan la Teoría del Delito - procedente en 
materia administrativa según la jurisprudencia nacional e internacional- sólo la ley puede establecer conductas y sanciones. No es función del ejecutivo definir conductas y sanciones, sino efectivamente sancionar cuando exista una ley dictada formalmente por la Asamblea Legislativa, tal como se interpreta el artículo 14 de la Constitución. Contrariamente la ley de armas prueba que no se siguen estos principios, tal como se constata en los ejemplos citados en las líneas previas respecto a los artículos 18,62 y 67 .

Precisamente, la sentencia de inconstitucionalidad 4-94 del 13 de junio de 1995 expresó que "la regulación de un derecho constitucional conforme el artículo 246 sólo pueden ser alterados por las leyes que regulen su ejercicio... el término ley se refiere a la ley en sentido formal..."

Aquella tesis de carácter absoluto, si bien ha sido modificada con una reciente opinión de la Sala de lo Constitucional en la sentencia 2-92 de fecha 26 de julio de 1999, mantiene su aplicabilidad en cuanto a la presente ley. El nuevo criterio sostiene, en referencia a la sentencia 4-94 citada en nuestro anterior párrafo: "Sin embargo, tal como aparece dicho precedente jurisprudencial puede conducir a un desconocimiento de las potestades normativas que la misma Constitución otorga a otros órganos estatales o entes públicos diferentes al Órgano Legislativo. Por ello resulta más adecuado interpretar el artículo 246, inc. 1 de la Constitución, en el sentido que únicamente se podrán limitar derechos fundamentales -establecer impedimentos o restricciones para su ejercicio- por ley en sentido formal, pero la regulación de derechos que comprenden titularidad, condiciones de ejercicio, manifestaciones y alcances del derecho, así como sus garantías, puede hacerse por cualquier norma de carácter general, impersonal y abstracta, siempre y cuando sea emitida por los órganos estatales o entes públicos con potestad normativa reconocida por Constitución, y que no se vulnere la prohibición establecida en el mismo artículo 246, inc. 1 de la Constitución, es decir, que no se altere el núcleo de los principios y derechos constitucionales".

Además se añade una práctica viciada de aplicar sanciones administrativa y penal a un mismo hecho. Baste para convencerse de la infracción a la Constitución lo dicho en el art. 11 de la misma: ninguna persona puede ser enjuiciada dos veces por la misma causa.
En nuestro país es escasa la jurisprudencia puntual al respecto; sin embargo, se cita la opinión de autores al respecto, en la sentencia 128-C-97 de la Sala de lo Contencioso Administrativo de la Corte Suprema de Justicia de las diez horas del 9 de julio de 1999, que sostienen que "se prohibe la aplicación de dos o más sanciones o el desarrollo de dos o más procedimientos, sea en uno o más órdenes sancionadores, cuando se dé una identidad de sujetos, hechos y fundamentos, y siempre que no exista una relación de supremacía especial de la Administración... que la problemática de intervención de dos órganos represivos puede darse, bien entre dos tribunales penales, entre dos administraciones públicas o entre un tribunal penal y un órgano administrativo".

En todo caso, la doctrina mayoritaria de los expositores del derecho y la jurisprudencia del Tribunal Constitucional Español - país cuya constitución sirvió de modelo a la nuestra-, han considerado que hay doble sanción cuando se castiga penal y administrativamente por una misma conducta. Por esa vía se pronuncia nuestra Ley de Procedimiento para la Imposición del Arresto o Multa Administrativos, en el inciso segundo del art. 3, que expresa que si la contravención a la ley, al reglamento o a la ordenanza constituye también delito o falta, deberá imponerse al culpable, por la autoridad judicial correspondiente, únicamente la pena que a tal infracción le corresponde de acuerdo al Código Penal. Solamente en algunos casos especiales hace excepciones la doctrina, como por ejemplo, tratándose de funcionarios públicos, a los que puede y debe aplicárseles doble sanción.

(d) Conforme el artículo 63, no pueden concederse licencias para uso de arma de fuego, matrículas de tenencia, portación de armas de fuego, entre otras, a las personas siguientes: Personas declaradas judicialmente en estado de interdicción y personas que sufran de limitaciones físicas o mentales, que razonablemente anulen o disminuyan su capacidad para el uso eficiente y seguro de un arma de fuego, de acuerdo a dictamen médico.

El problema es que en las disposiciones respectivas no se fijan condiciones, procedimientos o requisitos de exámenes profesionales o documentación para asegurar la comprobación de esos extremos.

Se conoce que en el proyecto original se excluían de las licencias y demás a los adictos al con- 
sumo de estupefacientes. Sin embargo, parece que el legislador considera que las autoridades correspondientes van a considerar como personas con limitaciones mentales, para hacer un uso eficiente y seguro de un arma, a los adictos.

(e) Conforme el artículo 75 de esta misma ley, si las armas están a disposición de la autoridad judicial se necesita de autorización previa para su destrucción. Esta destrucción debería estar sujeta a plazo, pues hay casos en que no están reclamadas por un juez, pero después resulta que han sido utilizadas en delitos. En ese sentido, debería facultarse a la Policía Nacional Civil para que mantenga armas en depósito por espacio de un año antes de su destrucción.

\section{Consideraciones de política criminal}

La ausencia de una política criminal básica hace que el legislador incurra en esta ley en una serie de contradicciones. La primera, y que más salta a la vista, es la de otorgar en la práctica funciones de seguridad a la Fuerza Armada. Aunque el artículo 217 de la Constitución es parte de la reforma constitucional pactada a raíz de los acuerdos de paz, lo cierto es que ha quedado obsoleto muy rápidamente. La precaución de dejar el control de las armas de fuego en manos del Ejército, para evitar cualquier rebrote de la guerrilla, no tiene hoy sentido y entorpece lo que deberían ser funciones de Seguridad, al menos duplicando funciones y engrosando los trámites necesarios en el momento que surjan problemas en la tenencia y portación de armas. Dado que el problema es Constitucional, la ley tendría que involucrar de momento a la Fuerza Armada, pero debería comenzar a estudiarse ya la reforma Constitucional del artículo mencionado, de modo que las tareas estrictamente de seguridad, como son la tenencia y portación de armas, se concentren en el Ministerio de Seguridad y en la Policía Nacional Civil.

El art. 63 expresa que no se podrán conceder licencias para uso de armas de fuego, matrículas de tenencia, portación de armas de fuego, entre otras, a los menores de 18 años. La edad para la tenencia particular de armas debería de elevarse todavía más. Las armas constituyen potencialmente una amenaza contra la vida humana, y la madurez que se debe exigir para su portación debe coincidir al menos con procesos de maduración personal elevados. En ese sentido, y exceptuando armamento estricto de competición o de caza, que pue- de ser tratado de otra manera, las armas de defensa y ataque no deberían estar en manos de ciudadanos particulares, sino hasta los 25 años. Otro es el caso de los soldados o de los jóvenes policías que gozan de una educación y supervisión especial para el uso de las mismas. Retrasar la edad es una manera de educar a la población con respecto a lo poco útil de la tenencia privada de armas como instrumento de solución de problemas de seguridad.

El aumento de armas en las calles en manos de civiles implica mayor incidencia de oportunidades para usarlas. Por ello más bien debería prohibirse de manera genérica la portación de armas en las calles, excepto para personas que por su oficio, cargo o circunstancias especiales (ser testigo, haber sido amenazado, transitar constantemente por lugares peligrosos, etc.) se autorice. Distinto es el caso de la tenencia de armas en casas u oficinas, en donde el riesgo de dañar a otros disminuye, si se observan medidas mínimas de precaución. Esto implica que el gobierno debe asumir mayores compromisos en la Seguridad Ciudadana y en acti-

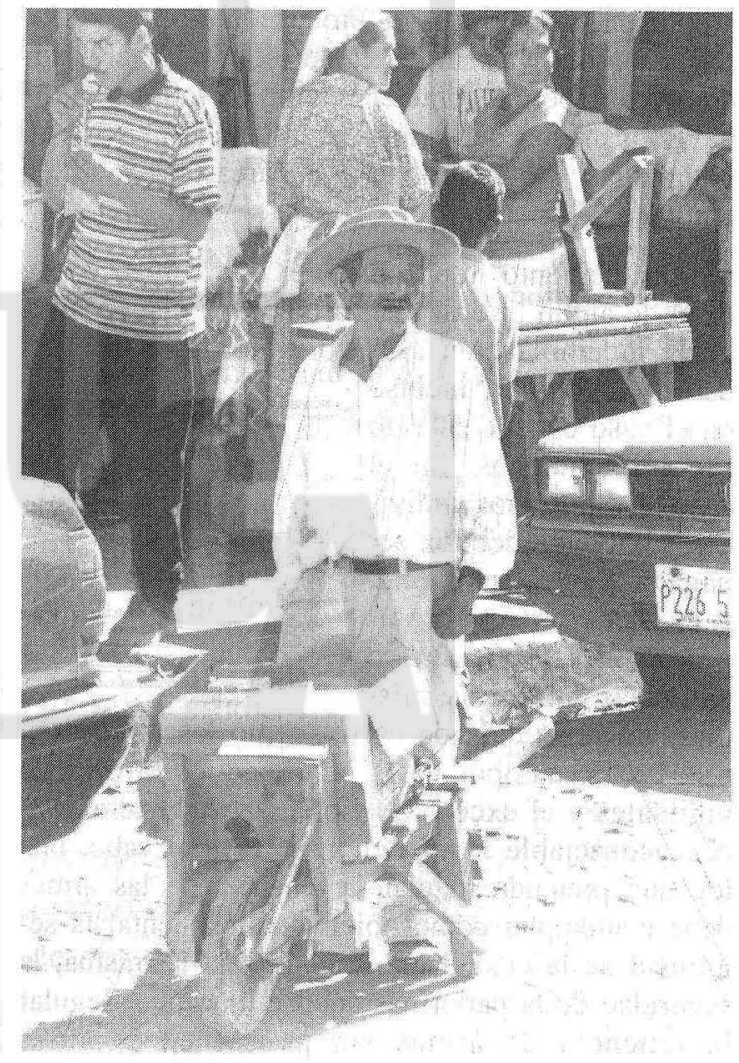


vidades de prevención, dentro de un Plan General de Política Criminal, para evitar que se acuda a facilitar a los ciudadanos poder de lesión o muerte en perjuicio de otros.

Una carencia grave en la ley actual, desde normas básicas de política criminal, es la ausencia del examen sicológico previo. La guerra ha dejado toda una serie de disfunciones sicológicas, especialmente en aquellos que tuvieron a lo largo de la misma el uso frecuente de armamento, o en personas que padecieron el uso injusto de armas por cualquiera de los dos sectores contendientes. Así mismo, la criminalidad nos indica la existencia de un uso patológico de las armas por parte de una proporción alta de la ciudadanía. Hechos relativamente frecuentes, como el de sacar pistola, e incluso usarla en discusiones tan nimias como el derecho de vía, nos muestran grados de agresividad incompatibles con el uso responsable de armas defensivas. Exigir una evaluación sicológica previa se vuelve así una condición indispensable para dar pasos hacia una adecuada restricción del uso del armamento. Al mismo tiempo, ello incorporaría a la profesión de los sicólogos, debidamente supervisada por su Junta de Vigilancia, a una labor de protección de la ciudadanía cada día más urgente. A esta evaluación sicológica deberían someterse también todos los que vayan a prestar servicios de vigilancia armada en compañías de seguridad o en áreas privadas de empresa.

Un elemento importante del que carece la ley es el de algún tipo de fianza o seguro que garantice la indemnización a posibles víctimas del mal uso de las armas, incluso en el caso en que éste no fuera intencional. En el caso del portador individual, la fianza debería ser pagada por el individuo, $y$ en el caso de las compañías de seguridad o empresas por estas mis-

mas. La repetición de casos, como las heridas en niños causadas por balas perdidas, los errores de vigilantes y el exceso de violencia en general, hacen aconsejable la medida. Al fin y al cabo, una ley que pretenda regular la tenencia de las armas debe contemplar como objetivo fundamental la seguridad de la ciudadanía $y$, dentro de la misma, la seguridad de la parte más débil e inocente. Regular la tenencia de armas sin pensar en posibles indemnizaciones sería corromper el sentido último que debe tener una ley de este tipo.

Finalmente, y siempre dentro de las líneas que debían seguirse en una adecuada política criminal, la ley debería contener un apartado directamente relacionado a la portación de armas bajo efectos de drogas o bebidas alcohólicas. Los análisis hechos sobre la práctica criminal nos dejan ver que muchos de los hechos delictivos cometidos con armas de fuego se fraguan al calor del alcohol o de otro tipo de drogas, pero preferentemente al calor del primero. En un estudio realizado por la UCA en los hospitales Rosales y de San Bartolo, la proporción de ingresos de heridos bajo efectos del alcohol constituía un 22 por ciento a lo largo de una semana normal. En las semanas festivas la proporción aumentaba a un 41 por ciento de los heridos. Las personas que fueran descubiertas portando armas y en situación de embriaguez o drogadicción, deberían ser penadas con mayor rigor y perder su licencia de portación de armas. Si a la hora de manejar vehículos se ponen límites para la conducción bajo el efecto del alcohol, dado el uso abusivo que se hace de las armas, debería con la misma lógica sancionarse severamente la simple portación en dicha situación.

\section{Símbolos y actitudes políticas}

Toda ley tiene su contenido simbólico. La ley de protección del menor, por ejemplo, trata de hacernos conscientes de los derechos especiales de quienes son menores de edad y de la responsabilidad de la sociedad adulta para con ellos. Ante el menor no se puede ser vindicativo sino fundamentalmente educativo. Por ello la ley del menor da privilegios especiales a los mismos en comparación con las leyes que penan a los adultos. 
adultos al crimen, apaleado y tratado como cosa en vez de como persona, recibiendo presiones y maltrato en vez de estímulos positivos, compensa las desventajas que de la misma ley se puedan seguir. Estar en contra de esta ley en su totalidad, aunque se puedan reformar algunos aspectos, equivaldría a estar a favor de una sociedad en la que la ley del más fuerte se impone sobre los débiles.

El menor es además más fácilmente reeducable $y$ reintegrable en la sociedad. No tener en cuenta estos aspectos, humanistas, sicológicos, educativos y prospectivos de una posible readaptación sería un error grave en una ley de este tipo. Y enviaría a
El aumento de armas en las calles en manos de civiles implica mayor incidencia de oportunidades para usarlas. Por ello más bien debería prohibirse de manera genérica la portación de armas en las calles, excepto para personas que por su oficio, cargo o circunstancias especiales (...) se autorice. siempre peligroso. Solamente personas debidamente supervisadas, integradas en funciones de seguridad, con adecuados niveles profesionales y técnicos, y sujetas a entrenamiento y evaluación permanente por parte de instituciones estatales, tendrían opción al uso de armas. Armas que, en definitiva, no pueden considerarse como un bien sino como un mal en ocasiones necesario, $y$ que, por tanto, debe ser claramente controlado.

Sin embargo, de la lectura de la actual ley no surge el contenido simbólico que mencionamos. La mención de la verdadera paz social no es más que un adorno inicial. La facilidad la juventud un mensaje simbólicamente nefasto: la afirmación de una sociedad autoritaria que castiga con mayor rudeza al más débil mientras que el fuerte puede quedar en la impunidad.

De la misma manera, la actual ley de armas tiene su contenido simbólico. En teoría, dicho contenido debía expresar la convicción de que la fuerza física coactiva debe permanecer como monopolio de un Estado que está al mismo tiempo sometido a las leyes. El ciudadano tiene su seguridad física puesta en las leyes y en las instituciones que están encargadas de velar por su cumplimiento, no en su capacidad de acceder a armas ofensivo defensivas, o de conseguir, mediante dinero, un nutrido cuerpo de guardaespaldas. Las excepciones a dicho monopolio deben estar claramente delimitadas en la ley que, por definición, debe ser restrictiva $y$ no permisiva: La ley podría estar abierta a funciones subsidiarias de instituciones privadas de seguridad, siempre bajo supervisión y normativa estatal. La idea central de la ley de armas sería proteger al ciudadano de un tipo de instrumento, el arma de fuego, que es
Una carencia grave en la ley actual, desde normas básicas de política criminal, es la ausencia del examen sicológico previo. La guerra ha dejado toda una serie de disfunciones sicológicas, especialmente en aquellos que tuvieron a lo largo de la misma el uso frecuente de armamento...
Este modo de pensar se expresa con claridad simbólica en el art. 72. En él se facilita la compra y portación de armas, incluso las de uso privativo de la Fuerza Armada, para un nutrido grupo de funcionarios y su escolta. Aunque la compra y portación de armas para la seguridad de los funcionarios de alto rango debe ser facilitada por la ley ( $\sin$ exceptuar la eva- 
luación sicológica de los escoltas, por protección de los mismos funcionarios), los funcionarios en cuanto tales no deberían ser tratados por la ley con consideraciones excepcionales. Funcionarios como el Presidente de la República, los Magistrados de la Corte Suprema y Cámaras de Segunda Instancia, no digamos el Procurador de Derechos Humanos, son de alguna manera símbolos de la convivencia nacional, de la moralidad y de los valores que deben regir la misma convivencia. Otorgarles la posibilidad de armarse con más facilidad que el resto de los ciudadanos ofrece un pésimo ejemplo a la ciudadanía. Por un lado se presenta a quienes son símbolo de convivencia pacífica y basada en leyes, como a personas que pueden contestar con el peso de las armas a cualquier agresión. $Y$ por otro se da un nefasto ejemplo: Si los que gozan de mayor posibilidad de protección tienen incluso el recurso legal de armarse personalmente, es que algo falla en los sistemas de seguridad ciudadana.

Otros factores, como el de considerar que quienes están en puestos superiores tienen automáticamente la posibilidad de armarse hasta los dientes en medio de una sociedad predominantemente civil y que quiere crecer en su civilidad, dejan el esfuerzo por construir el Estado de derecho mal parado. Porque para quienes tienen supuestamente garantizada su seguridad por la policía, y son simultáneamente símbolos de pacífica convivencia, no debería tener sentido el armarse individualmente.

A esta dimensión simbólica se suman las opiniones de trascendencia política. El presidente de la Corte Suprema ha manifestado sus críticas a esta ley con claridad cívica y mentalidad moderna. Al contrario, el Sr. Presidente de la República ha manifestado que no tiene objeciones de fondo a la ley de armas. Frente a un Presidente de la Corte coherente con su responsabilidad política y su papel simbólico en el Estado de derecho, el presidente de la República muestra tanto una seria irresponsabilidad en el campo de la reflexión política, justificando la ley con frases tan faltas de contenido como la de "lo perfecto es enemigo de lo bueno", como una ignorancia del papel que le corresponde como presidente de todos los salvadoreños. Papel de defender a los más débiles, a los que no usan ni usarán armas y que, por tanto, prefieren que el uso de las mismas esté rigurosa, restrictiva y seriamente controlado. Si hemos optado como ciudadanos de un Estado de derecho en favor de que el monopolio de la fuerza física resida en el Ejecutivo, no tiene mayor sentido el privatizar la seguridad con tanta facilidad y tantos riesgos. Llegando incluso a ofrecer a los funcionarios el absurdo recurso de privatizar su propia seguridad.

\section{Conclusión}

Todo hace suponer, cerrando ya nuestros comentarios, que la actual ley de armas es una concesión más a quienes están en el negocio de las mismas. En reportajes de La Prensa Gráfica se habla de que hay en el país un arma por cada 20 habitantes. Un titular del mismo periódico aseveraba que cada mes entraban en el país 1000 armas. $Y$ en un recuadro cuya fuente era el Ministerio de Defensa se decía que había en el país 27 empresas que importaban y comercializaban armas, y que para el año 1999 se había autorizado la importación de 36000 diferentes tipos de armas y 11 millones de unidades de munición. El negocio de las armas medra en medio de la violencia creando una cultura que, a su vez, alimenta la misma violencia imperante.

Las consideraciones éticas, que hablan de la importancia de restringir el uso de armas en una sociedad traumada por la violencia y endurecida en el uso de la misma hasta extremos sumamente crueles, no han pesado en la elaboración de esta ley. Como tampoco ha jugado un papel la racionalidad que habla del necesario monopolio estatal de la fuerza física, tanto más necesario cuanto mayor es la violencia imperante. Tampoco la ley ha querido esperar a la elaboración de una política criminal que fomente en primer lugar, y como respuesta de emergencia, un renovado esfuerzo en la formación (general y especializada), depuración y ampliación de la Policía Nacional Civil, como garan- 
te de la seguridad ciudadana. Al contrario, se ha preferido ceder ante las necias imágenes de ciudadanos defendiéndose en plan "Rambo", y ante los intereses de un negocio bien establecido que tiene como único contrapeso el tráfico ilegal de armas.

Ante el exceso de armas en manos de ciudadanos, y ante el mal uso de las mismas, se pueden dar, muy en síntesis, tres posiciones: la primera la de la permisividad absoluta. La segunda consistiría en facilitar la legalización de las armas y restringir simultáneamente la tenencia ilegal. Y la tercera trataría de restringir al mismo tiempo la tenencia legal y la ilegal. Los diputados y el gobiemo, para responder a una ciudadanía harta de la violencia y molesta con la permisividad casi absoluta en el tema de la tenen- cia y portación, han optado por la segunda de las posiciones mencionadas, saltándose incluso algunas formalidades jurídicas de fondo que deberían ser tenidas en cuenta en un Estado que se pretende de Derecho. A nuestro juicio, la ley debería estar en sintonía, básicamente, con la tercera de las posiciones enunciadas. El aporte de la nueva ley al necesario combate de la violencia imperante puede desde ahora calificarse como minimo, cuando no nulo.

Pensar que el "buen ciudadano" armado se convertirá en freno para la delincuencia tiene un cierto paralelismo con el espectáculo reciente de sacar tanquetas a la calle para combatir rateros. El paralelismo de la demagogia y la manipulación de la realidad puesta al servicio de otros intereses. 